Revista Educação e Políticas em Debate - v. 10, n. 2, p. 575-594, mai./ago. 2021 - ISSN 2238-8346

\title{
Determinantes político-pedagógicos em um programa oficial de formação docente para a alfabetização
}

\author{
Political-pedagogical determinants in an official teacher training program for literacy \\ Déterminants polito-pédagogiques dans le cadre d'un programme officiel de formation des enseignants \\ à l'alphabétisation
}

Mirella de Oliveira Freitas ${ }^{1}$

Universidade Federal de Uberlândia

\begin{abstract}
Resumo: Este artigo analisa como as dimensões linguística e textual-discursiva foram associadas nas propostas didático-metodológicas do Pacto Nacional pela Alfabetização na Idade Certa (PNAIC), um programa oficial de formação docente continuada, lançado em 2012 e extinto em 2018. Por meio de pesquisa documental qualitativa, investigaram-se os cadernos formativos estudados em 2013, voltados ao ensino-aprendizagem da língua materna. Resgatase o programa visando-se a contribuir com as demandas atuais de fortalecimento dos estudos dos letramentos, diante da defesa de uma alfabetização tecnicista e supostamente neutra. Os resultados indicam desafios quanto à articulação das referidas dimensões, para que se aproximem as práticas escolares das situações de interação social mais amplas.
\end{abstract}

Palavras-chave: Políticas públicas educacionais. Formação de professores. Alfabetização na perspectiva do letramento.

Abstract: This article analyzes how the linguistic and textual-discursive dimensions were associated with the didactic-methodological proposals of the Pacto Nacional pela Alfabetização na Idade Certa (PNAIC), an official Brazilian program of continuing teacher training, launched in 2012 and came to an end in 2018. Through qualitative and documentary research, we investigated the formative notebooks of the program from 2013, focused on the Portuguese Language (beginning literacy, reading and writing). The program is brought back in order to contribute to the current demands of strengthening literacy studies, in the face of the defense of a technical and supposedly neutral literacy. The results indicate challenges regarding the articulation of these dimensions as a means of bringing school practices closer to broader social interaction situations.

Keywords: Educational public policies. Teacher education. Literacy perspective.

Résumé: Cet article analyse la manière comment les dimensions linguistiques et textuellesdiscursives ont été associées dans les propositions didactiques-méthodologistes du Pacte National par l'Alphabétisation à l'Âge Correcte (PNAIC), un programme officiel de formation continue des enseignants, lancé en 2012 et terminé en 2018. À travers une recherche documentaire qualitative, les cahiers de formation étudiés en 2013 ont été examinés, ces cahiers étaient destinés à l'enseignement-apprentissage de la langue maternelle. Le programme est sauvé ayant comme but de contribuer avec les demandes actuelles de renforcement des études de littératie, face à la défense d'une alphabétisation technique et apparemment neutre. Les

1 Doutora em Letras pela Universidade Federal do Tocantins. E-mail: mirellafreitas@ufu.br. Lattes: http://lattes.cnpq.br/7083726112814657. ORCID: https://orcid.org/0000-0001-8169-8292. 
Revista Educação e Políticas em Debate - v. 10, n. 2, p. 575-594, mai./ago. 2021 - ISSN 2238-8346

résultats indiquent des défis par rapport à l'articulation de ces dimensions, afin de rapprocher les pratiques scolaires des situations d'interaction sociale plus larges.

Mots-clés: Politiques publiques d'éducation. Formation des enseignants. Alphabétisation dans la perspective de la littératie.

Recebido em: 23 de abril de 2021 Aceito em: 17 de junho de 2021

\section{Introdução}

Debates sobre alfabetização têm se mantido na agenda das políticas públicas educacionais, haja vista tratar-se de um direito social ainda não garantido a todos os brasileiros. Recentemente, o tema ganhou destaque nos polêmicos discursos do presidente Jair Messias Bolsonaro e de membros de sua equipe, quando defenderam paradigmas metodológicos para o ensino-aprendizagem do sistema de escrita alfabética e ortográfica (SEA), mas repudiando a associação com os usos sociais da língua para além das práticas escolares. Na oportunidade, ainda enunciaram objeções a Paulo Freire, aos estudos dos letramentos e às abordagens construtivistas (cf. discute SILVA, 2021).

À vista, então, da atualidade do tema, tecemos reflexões sobre o Pacto Nacional pela Alfabetização na Idade Certa (PNAIC) como política pública, reflexões estas informadas pelo campo de estudos indisciplinar da Linguística Aplicada (MOITA LOPES, 2009)². O programa foi extinto, mas representou um marco na formação de professores, com o diferencial de ser longevo (com duração inicial prevista para 3 anos) e de integrar ações, materiais e referências curriculares e pedagógicas do Ministério da Educação (MEC). Sua proposta visava a contribuir para a alfabetização na perspectiva do letramento a partir da formação continuada de professores alfabetizadores em serviço. Retomá-lo no presente momento político, marcado por desafios e retrocessos, torna clara a educação como palco de movimentos partidários, ao mesmo tempo em que ratifica a necessidade de ela se impor como espaço para a formação crítica de produtores de mudanças em defesa da democracia.

Delineado por esse contexto, este artigo relata uma investigação documental de natureza qualitativa. $\mathrm{O}$ recorte investigativo centrou-se nos cadernos formativos do PNAIC estudados em 2013, ano em que se focalizou o ensino-aprendizagem da língua materna. A análise se concentrou no aporte teórico que compôs esse material e nas atividades didáticas relatadas nele, como exemplos de práticas exitosas de alfabetização associada ao letramento. O objetivo foi divisar como as dimensões linguística e textual-discursiva se associaram no

\footnotetext{
${ }^{2}$ Este artigo retoma resultados da tese de doutoramento da autora (FREITAS, 2019).
} 
contexto do programa, como reflexo da política de alfabetização no Brasil e de influências de natureza acadêmico-educacional, histórica e ideológica.

A teoria Ator-Rede $(\mathrm{ANT})^{3}$ foi importante parâmetro metodológico para a análise interpretativista, ao permitir que se divisasse a rede multifacetada e complexa de que o PNAIC participou e que compreende o constante movimento político-pedagógico que envolve o campo educacional. À vista desse delineamento, além dos trabalhos de Latour (2012) e Pinto (2016), tomamos como arcabouço teórico os estudos de Soares (1998, 2003a, 2003d, 2004, 2009, 2016, 2017), nos quais a autora aborda os conceitos de alfabetização, letramento, alfabetizar letrando ou em contexto de letramento, e em que argumenta em favor do resgate das especificidades da alfabetização nos anos iniciais do ensino fundamental. Também, dialogamos com as pesquisas de Morais (2005, 2012, 2013), um dos autores dos documentos analisados e pesquisador de referência nacional no campo da alfabetização, dedicando-se a propostas metodológicas de reflexão sobre o sistema de escrita. No que se refere à abordagem da prática social de escrita, foram relevantes os estudos de Street (2014), um dos influenciadores dos estudos dos letramentos no Brasil. Esses, além de autores outros que alicerçaram as discussões sob a perspectiva crítica da Linguística Aplicada (LA) e da área das políticas públicas.

Os limites disciplinares se rompem, portanto, articulando diversas vozes e olhares, em consonância com o que afirma Moita Lopes (2009, p. 16), que "nenhuma área do conhecimento pode dar conta da teorização necessária para compreender os processos envolvidos nas ações de ensinar/aprender línguas em sala de aula devido a sua complexidade”. É o contexto de análise determinando a teoria.

\section{Contexto de pesquisa e procedimentos metodológicos}

O PNAIC foi um programa de formação docente continuada, instituído em 2012 pela Portaria n. 867, de 4 de julho; portanto, no primeiro governo de Dilma Roussef (2010-2014). Como política de continuidade, manteve-se durante o governo do presidente Michel Temer (2016-2018), mas sofrendo mudanças importantes. O programa assumiu a configuração de formação em rede, sendo presidido pelo MEC e contando com a cooperação das universidades públicas (responsáveis pela gestão acadêmica e pedagógica) e das secretarias estaduais e municipais de educação (que coordenavam e monitoravam as ações locais), além do Distrito Federal.

\footnotetext{
${ }^{3}$ Acrônimo ANT, referente à denominação em inglês Actor-network Theory. Os principais expoentes da teoria são os sociólogos Bruno Latour, John Law e Michel Callon.
} 
Os esforços conjuntos visavam a garantir a alfabetização das crianças até os 8 anos de idade, ou seja, até o final do $3^{\circ}$ ano do ensino fundamental - período, aliás, alterado recentemente para o $2^{\circ}$ ano, com a publicação da Base Nacional Comum Curricular (BNCC). O centro das formações eram professores alfabetizadores, docentes dos três primeiros anos do ensino fundamental das redes públicas municipal e estadual de ensino.

Dentre os vários materiais didáticos previstos e disponibilizados para auxiliar no processo de ensino-aprendizagem e no próprio curso, 35 cadernos ou unidades foram elaborados especificamente para atender aos propósitos formativos delineados para o PNAIC em 2013. Desse conjunto, 26 fascículos foram examinados pela investigação relatada neste artigo: dois cadernos de abordagens gerais, estudados por todo o grupo de orientadores e professores (um caderno de apresentação dos princípios gerais do programa e outro de apresentação e discussão de estratégias formativas); e oito cadernos ou unidades para cada curso $\left(1^{\circ}, 2^{\circ}\right.$ e $3^{\circ}$ anos do ensino fundamental; portanto, 24 fascículos), contendo, principalmente, textos teóricos sobre os temas da formação, relatos de professores da educação básica e sugestões de atividades" ${ }^{4}$.

Os cadernos formativos foram a via de acesso à rede de atores que circundam o PNAIC, que o definem e são por ele definidos. Dizemos rede de atores em referência à Teoria AtorRede (ANT) de Latour (2012), autor este que compreende o “domínio social” não como um estado estável das coisas, mas como uma complexa rede de elementos heterogêneos que estão continuamente se recompondo e se reassociando. Os elementos relacionados são os actantes, que podem ser humanos e não-humanos. Os cadernos inserem-se nessa rede, contribuindo, sobremaneira, para a mudança no "estado das coisas".

Sob esse viés, o programa não agrega uma única perspectiva e pode até mesmo tentar (cor)responder a discursos que não são uníssonos. Por isso, afirmamos ainda que as práticas pedagógicas de alfabetização e letramento no contex to do programa e nas salas de aula da educação básica são induzidas pela reunião de uma série de elementos que se relacionam: instâncias governamentais, movimentação burocrática e organizacional, perspectivas metodológicas dos professores e da equipe gestora, domínios teóricos, espaço físico em que se realizam, conhecimentos e vivências culturais, dentre tantos outros elementos.

Nessa perspectiva, os cadernos analisados não são, única e diretamente, meros produtos da ação humana. Eles são um híbrido de vozes de diversas instâncias, de concepções, perspectivas, objetivos, memórias e vivências; há todo um conjunto de actantes que é

\footnotetext{
${ }^{4}$ Não foram inclusos na análise os fascículos voltados à Educação do Campo e à Educação Especial. São áreas de estudo específicas já consolidadas e cuja abordagem envolve outros enfoques teóricos.
} 
mobilizado e que se mistura na materialidade escrita. A alguns deles, este estudo dá maior visibilidade, como as instâncias governamentais e seus interesses e os estudos acadêmicocientíficos dedicados às áreas de alfabetização e letramento.

No que diz respeito às concepções teóricas que orientam esse material, elas também estão imbricadas em uma densa rede de determinantes. Sob a perspectiva da ANT, a proposta de se alfabetizar letrando, na perspectiva do letramento ou em contexto de letramento são conhecimentos consolidados, ao que Latour denomina de "caixas-pretas" (PINTO, 2016; LATOUR, 2012). Abrimos, assim, a caixa referente a esses conceitos, problematizando-os a partir da proposta de alfabetização e letramento no contex to do PNAIC. Aliás, Soares (2017) alerta para o fato de existir, na verdade, apenas um suposto pacifismo quanto ao significado dessas expressões, devido às posições teóricas assumidas por muitos autores. Mas, segundo ela, os termos se mantêm polêmicos, uma vez que jamais se venceu o fracasso em se alfabetizar e letrar crianças brasileiras.

O PNAIC é, assim, um agregado social, inter-relacionado a inumeráveis elementos, a partir dos quais o programa poder ser compreendido. A rede que o envolve e da qual participa é inesgotável. Entretanto, um recorte representativo do contexto que o cerca dá legitimidade ao objeto de estudo desta investigação, mostrando-o atravessado por elementos heterogêneos. Os domínios do programa vão além da sala de aula; os sujeitos que dele participam são heterogêneos, constituintes e constituídos de um contex to social fluido, constantemente mutável e marcado pelas relações de poder, enquanto forças de controle, de natureza sócio-histórica (PENNYCOOK, 2001).

Portanto, conforme Freire (1989), impossível pensar uma educação que seja neutra. Segundo o autor, se tudo é política e historicamente definido, também os contextos de ensino e aprendizagem de línguas o são; o poder é inerente às questões discursivas. $O$ desafio, portanto, é encontrar seus rastros na rede do PNAIC, materializada nos cadernos formativos. Afinal, conforme Latour (2012), a dinâmica do sistema que sustenta uma rede de actantes é tal qual uma encenação num palco: não é possível definir quantas pessoas agem simultaneamente num indivíduo; ainda que ele se apresente sozinho, não fica totalmente claro quem ou o que está atuando. Todos os elementos se compõem e se afetam mutuamente.

\section{O programa no contexto histórico das políticas públicas educacionais}

A educação escolar no Brasil tem um histórico de exclusão e de carências. Já nos primórdios do país, quando este ainda era colônia, a educação era direito exclusivo dos europeus que ocuparam as terras brasileiras. Por muito tempo, negou-se aos escravos o direito de estudar e, aos indígenas, nativos, dedicou-se uma educação restrita, de cunho mais 
catequizador. Quanto aos recursos básicos para uma educação de qualidade, quando o ensino passou a ser de responsabilidade do Estado com a expulsão dos jesuítas em 1759, o cenário era de profissionais despreparados, escassez de recursos financeiros e recomeço à organização da educação no país. Ademais, o pouco que se aprendia tinha caráter experimental, visando-se a formar mão-de-obra para pequenos cargos burocráticos (LEÃO, 2005). Foi essa ascendência que delineou a formação de uma sociedade organizada hierarquicamente, segundo o acesso ao ensino da leitura e da escrita, e que, por consequência, imputou carências educacionais e sociais que permanecem até os dias de hoje.

Entretanto, é o nível educacional de um país que define categorias político-econômicas mundiais, o que justifica a busca constante do Brasil por melhores índices na educação nacional. Assim, diante da precariedade perdurável, a cada novo governo, sempre à vista da urgência, lança-se uma nova proposta político-educacional que, de certa forma, configura-se num recomeço ou até mesmo num retrocesso que lança por terra os esforços anteriores. Em todos os âmbitos, contudo, as medidas acabam se mostrando insuficientes, porque, além de isoladas de outros setores igualmente relevantes, no geral, visam a reconhecimento mundial e lucros, em detrimento de uma formação para o exercício pleno da cidadania, para o bem comum, para desenvolvimento e satisfação pessoais. Contribuem, assim, para se manter a conjuntura já estabelecida, com prejuízos permanentes em termos de infraestrutura, valorização do profissional da educação, acesso à escola e progressão nos estudos. Historicamente, então, as políticas educacionais tendem a ser excludentes e parciais.

Especialmente a partir de 1990, surgem novas demandas no quadro educacional, devido ao fortalecimento de agências internacionais e a mudanças globais e tecnológicas (VIEIRA, 2016), o que faz com que as políticas públicas passem a visar a formação docente. Também ocorrem mudanças nas formas de avaliação; a aprendizagem deixa de ser mensurada no contexto particular da escola e os insucessos passam a ser evidenciados em avaliações sistêmicas externas. Quanto ao acesso à escola, o país legitima a universalização da educação básica em 2009, que passa a ser obrigatória e gratuita entre os 4 e 17 anos de idade, ou seja, desde a educação infantil até o término do ensino médio (Emenda Constitucional 59/2009). Além disso, acirram-se as discussões sobre currículo no âmbito político e ganham notoriedade os conceitos de alfabetização e letramento, sobretudo entre 2005 e 2010 (PERES, 2016).

Tendo esse cenário como pano de fundo, o PNAIC foi lançado em 2012 e implantado em 2013. Atendeu a uma das diretrizes do Plano Nacional de Educação 2014-2024, a qual prevê a superação das desigualdades educacionais por meio da erradicação do analfabetismo e de todas as formas de discriminação até o final do decênio. Visando a esse propósito, uma 
das ações apresentadas no documento era, além da implantação do programa, a realização de avaliações para aferir os níveis de alfabetização e letramento em língua portuguesa (leitura e escrita) e matemática (numeramento), aplicadas a estudantes dos três primeiros anos do ensino fundamental. Isso aconteceu por meio da Avaliação Nacional da Alfabetização (ANA), aplicada até 2016 e extinta em $2018^{5}$.

Obviamente, um programa, por si mesmo e num curto período, não pode mudar todo o complexo contex to que se constituiu historicamente no país, especialmente se considerarmos a rede de elementos que se somam para o estabelecimento de realidades. A despeito disso, a própria ANA acabou servindo ao governo como justificativa para questionar a eficácia do programa já a partir da edição de 2016, ou seja, do ponto de vista histórico, um curto período depois da implantação do PNAIC. À vista dos resultados tidos como pouco expressivos, alterou-se a estrutura e a abrangência do programa, mas reafirmando-se o foco no professor. Alegou-se formação distanciada da prática e centrada nas universidades.

Entretanto, os índices são apenas um dos atores relacionados aos resultados do programa. Eles são a dimensão que atende prioritariamente aos interesses políticoeconômicos. O próprio documento orientador do PNAIC - 2017 (BRASIL, 2017c) cita outros parâmetros igualmente importantes e que validam as ações empreendidas. Um deles é o fortalecimento do professor, que desenvolve mais autonomia para suas ações e se sente mais competente na busca por estratégias e recursos didáticos e no uso destes, isso independentemente de mudanças políticas. $\mathrm{O}$ outro parâmetro diz respeito à conquista do apoio da direção escolar e da coordenação pedagógica ao compromisso de se alfabetizar a todas as crianças. Essas conquistas, entretanto, não foram consideradas.

Além de se prender a apenas uma das referências - no caso, os resultados nas avaliações sistemáticas, de interesse político-econômico -, o governo acabou insistindo no saber fazer do professor, evidenciando-lhe a competência profissional. Isso acabou sendo reforçado com a aplicação da própria ANA, que, segundo Dickel (2016), tinha como propósito apresentar um diagnóstico, mas também mobilizar a equipe escolar para melhorias na educação. Aliás, o resultado da prova era composto ainda de informações contextuais, coletadas por meio de questionários aplicados a dirigentes, professores e diretores das escolas (Indicador de Nível Socioeconômico e Indicador de Formação Docente da escola). Os parâmetros de avaliação das respostas atribuídas, além de desconhecidos, pareciam tendenciosos, devido a algumas questões serem muito particulares de cada docente, segundo suas escolhas e identidade profissional (BRASIL, 2015a). Por exemplo,

\footnotetext{
${ }^{5}$ Desde então, todas as avaliações externas são identificadas como Saeb, Sistema de Avaliação da Educação Básica, e avalia-se alfabetização e letramento a cada 2 anos, na etapa final do segundo ano, não mais do terceiro. Também, todas as outras etapas escolares passaram a ser avaliadas, até mesmo a educação infantil.
} 
perguntava-se ao professor a frequência com que propunha ditados e cópias de textos. O que as respostas a questionamentos dessa natureza representam não fica claro aos respondentes.

Nesse sentido, então, o PNAIC também funcionou como mecanismo de controle das metas político-educacionais (ESTEBAN, 2012), e a avaliação ajudou a alimentar discursos que culpabilizam os docentes pelas mazelas, dissociando-as de outras imposições, como as questões de natureza social e de infraestrutura. Estas têm sido historicamente desconsideradas, embora reverberem no aproveitamento escolar.

Uma medida governamental realizada com o programa em andamento representou, particularmente, a opção por redução de gastos na educação como medida eficiente aos interesses econômicos. Já num processo de crise política instalada no país, o MEC deixou de enviar o material formativo a partir de 2016, sob a justificativa de conceder flexibilidade e autonomia às redes de ensino (BRASIL, 2016; 2017b); orientou que os materiais anteriormente produzidos e utilizados deveriam servir de inspiração para a produção de outros. Pareceu-nos, entretanto, a descontinuidade de uma proposta que havia se mostrado inaugural, escondendo-se a retirada do apoio às formações e a intenção de se reduzirem custos, o que se deu também com a considerável diminuição do período de formação. Em consequência disso, também houve impactos no pagamento de bolsas de estudo e pesquisa, previstas e instituídas a todos os envolvidos no processo formativo; de igual modo, no pagamento de diárias para aqueles que precisavam se locomover intermunicípios para participar dos encontros presenciais ${ }^{6}$. Ademais, segundo relatos de alguns professores alfabetizadores, tornou-se exaustiva a reposição das horas referentes ao período em que se ausentavam das escolas para as formações, já que, para saldá-las, trabalham em horários extras.

Outro fator que se soma às dificuldades já apresentadas foi a participação, nas formações, de professores contratados temporariamente pelas redes de ensino. Eles puderam permanecer vinculados ao programa apenas enquanto seus contratos se mantiveram vigentes, o que impediu que muitos finalizassem a formação (ANNUNCIATO, 2017). Essa, inclusive, foi uma realidade que contrastou com o discurso oficial do governo proponente do programa, que sugeria manter os mesmos professores durante todo o ciclo de alfabetização como estratégia de organização do trabalho docente e como garantia de condições mais favoráveis de planejamento em longo prazo, principalmente em se tratando de aprendizagens mais complexas (BRASIL, 2012c).

À vista de tudo isso, a cada ano o PNAIC formou menos alfabetizadores ${ }^{7}$. Embora se divisem mais investimentos no campo de ação das políticas públicas, ainda é latente a permanência

${ }^{6}$ Conforme a Medida Provisória n. 586, de 8 de novembro de 2012, convertida na Lei n. 12.801, de 24 de abril de 2013; a Resolução/CD/FNDE n. 4, de 27 de fevereiro de 2013, alterada pela Resolução/CD/FNDE n. 12, de 8 de maio de 2013; e a Portaria n. 90, de 6 de fevereiro de 2013.

${ }^{7}$ Os dados já estiveram acessíveis no sítio institucional http://pacto.mec.gov.br/historico-pnaic. Mas também foram registrados no Documento Orientador - PNAIC em Ação 2017 (BRASIL, 2017c). 
do déficit histórico na educação brasileira, haja vista os constantes desamparos e as questões de poder tão negativamente impactantes na escola. O compromisso político parece-nos, então, sempre restrito, limitado a conveniências partidárias e econômicas. Em consonância com a teoria de redes que nos serve de apoio metodológico, isso é reflexo da ação concomitante de uma série de elementos que se relacionam e que se impactam, acarretando inumeráveis condições. A indissociabilidade desses elementos permite-nos entender a complexidade do cenário políticoeducacional, bem como o porquê de as práticas de linguagem serem estabelecidas e trabalhadas dentro de uma dada perspectiva em algum espaço-tempo. No contexto do programa, elas revelam interesses de alguns atores particulares, nem sempre concordantes, o que se manifesta também na própria proposta pedagógica, discutida na seção a seguir.

\section{Entre novas e velhas práticas de linguagem}

Pensar a alfabetização na perspectiva do letramento implica o ensino sistemático do SEA associado a práticas de leitura e escrita que visem a atingir algum propósito num dado contexto social, contex to este que as determina, impondo forma e estilo de linguagem. Conforme esclarece Soares (2009, p. 75), significa usar a língua escrita como resposta a "o quê, como, quando e por quê ler e escrever". Assim, considerando-se um relativo afastamento conceitual entre os termos, pedagogicamente, trabalham-se as habilidades compreendidas pela alfabetização - em sentido estrito, competência técnica e motora para a realização da escrita e da leitura e compreensão das propriedades do sistema notacional e dos princípios que o regem (SOARES, 2003a; ALBUQUERQUE; MORAIS; FERREIRA, 2013) -, relacionando-as a interações sociais mediadas pela escrita, com as quais as crianças têm contato antes mesmo da escolarização.

É essa concepção que orienta a proposta pedagógica do PNAIC, apoiada nos trabalhos de Soares (1998; 2003b; 2003c; 2004; 2006) e em outras bibliografias referenciadas nos cadernos (como MORAIS; ALBUQUERQUE, 2004; 2010), mas que também têm como precedente os estudos da autora. Nos fascículos formativos, fala-se em "alfabetizar letrando" (expressão utilizada 19 vezes em 9 dos cadernos analisados) e em "alfabetizar" ou "alfabetização na perspectiva do letramento" (construção empregada 43 vezes; só não em 4 dos 26 cadernos). Também se fala em integração ou em articulação dos processos, em práticas que se realizam ao mesmo tempo ou em simultaneidade.

Empregam-se, então, diferentes construções sintáticas as quais não compreendemos como sinonímicas. Em nossa leitura, elas implicam modos distintos de associação das dimensões de natureza linguística e textual-discursiva e têm reflexos diretos nas proposições de natureza escolar, além de refletirem a própria concepção de língua com que se trabalha e os objetivos pretendidos ao se empregá-la. 
A partir desse delineamento teórico-conceitual, para fins de exemplificação neste artigo, apresentamos três relatos constantes nos cadernos formativos que permitem divisar as possibilidades pedagógicas contempladas pelo programa para associação da faceta linguística - a que nos referimos como alfabetização, em sentido estrito - com as práticas de letramento - os usos sociais da escrita, para além daqueles caracteristicamente escolares. O primeiro deles ilustra a contemporaneidade ou a integração de ambas as dimensões no processo de ensino-aprendizagem da língua, mas focalizadas em momentos distintos ao longo da etapa escolar. O segundo exemplifica a articulação dessas práticas, realizadas concomitantemente, a um mesmo momento, de modo que uma serve à outra. Por fim, o terceiro excerto representa uma abordagem do letramento sob perspectiva mais crítica, abordagem esta que contribui para que os aprendizes se vejam como pertencentes a uma realidade, na qual podem e devem intervir por intermédio da escrita.

\section{Exemplo 1}

Uma atividade interessante do LD [livro didático], que percebemos o quanto "surtiu efeito" na turma, foi a que trazia uma parlenda assim:

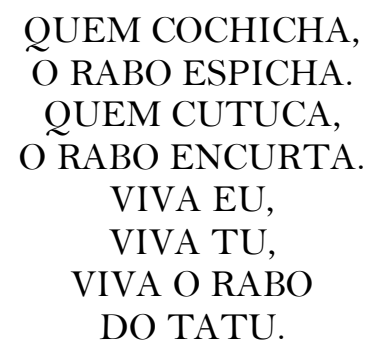

No primeiro momento, lemos para a turma um cartaz com a parlenda e a ilustração iguais às do livro. Destacamos a palavra TATU. Perguntamos à turma se alguém sabia o que era um tatu. A maioria disse que sabia [ $\ldots .$.$] .$

Indaguei se alguém sabia onde estava escrita a palavra "TATU". 50\% da turma acertou, apontando com o dedo para a palavra no cartaz. Em seguida, perguntei sobre o que essas palavras tinham em comum: "COCHICHA e ESPICHA" e "ESCUTA e ENCURTA". Um deles me respondeu pensativo:

- O..."CHA"?? O "CHA" DE "COCHICHA" é o mesmo de "ESPICHA". Vê, tia: CO-CHI-CHA, ES-PI-CHA (falando mais alto a última sílaba das duas palavras).

- Muito bem! - respondi, sorrindo. E "ESCUTA e ENCURTA”? - indaguei.

Muitos ficaram repetindo silabando, uns baixinho e outros mais alto:

- ES-CU-TA, EN-CUR-TA. Já sei tia, já sei tia, o "TA".

- Isso mesmo, o som final - respondi.

Perguntei se tinham outras palavras com esse som final, que não estavam no texto. Tainá disse:

- ENXUTA, CHUTA.

Através do cartaz, perguntei:

- E TU e TATU?

Todos em coro, rindo e tentando responder primeiro, falaram:

- O TU, tia, o TU... O TU, tia, o TU...

E foi assim que introduzimos o gênero textual PARLENDA, além de refletir sobre a questão sonora da rima, que já tínhamos explorado em outra aula, com um poema. Dando prosseguimento às atividades escritas do livro, pedi para os alunos sublinharem, no texto do livro, a palavra "TATU". Percebi que $90 \%$ dos alunos tiveram dificuldade nas atividades em que precisavam fazer a leitura 
sozinhos, e vi que, das sete atividades propostas no LD, quatro eram desse tipo. Passei de banca em banca para ajudá-los. Busquei dar destaque para a última questão do LD, que era para escrever palavras que rimassem com os nomes de figuras que apareciam ao lado das lacunas, onde a criança deveria escrever. (Ano 1, Unidade 3, p. 29-30.)

No relato, vemos usos da língua característicos do processo de ensino-aprendizagem da escrita, portanto, próprios da escola. Fala-se, então, em letramento, mas não na perspectiva social, conforme define Street (2014); é a pedagogização ou escolarização do letramento, ou, ainda, o letramento escolarizado. A atividade até envolve tex to de circulação social, comum no universo infantil, mas ignora as questões discursivas, que, espera-se, sejam abordadas noutro momento. Portanto, contextualiza-se a atividade ao se partir do texto, mas este como pretexto para abordagem da língua como objeto de estudo.

Práticas que assim se configuram representam, sob nossa leitura, apenas a integração das facetas, a que se refere Soares (2009; 2016), ou seja, a inclusão de ambas as dimensões - de alfabetizar e letrar - no processo tradicionalmente conhecido como alfabetização. Nesse sentido, a escola dedica-se tanto ao ensino-aprendizagem das relações fonografêmicas quanto ao trabalho com textos escritos ou mediados pela escrita, ao longo do período de alfabetização, não necessariamente de modo síncrono, numa mesma atividade didática. Seriam, pois, ações contemporâneas, realizadas paralelamente, ora focalizando-se uma das dimensões, ora outra.

Esse formato de abordagem faz sobressair a concepção de língua como código, como objeto, sendo ela trabalhada a partir de uma abordagem tecnicista, que coloca em evidência as convenções, não naturalmente aprendidas. Em certa medida, autorizam ainda a compreensão de que as habilidades relativas ao letramento social poderão vir, sem prejuízos, a posteriori, postergando-se a conscientização de que se escreve e se lê para participar de uma amplitude de contextos sociais marcados por particularidades. Aliás, contextos de que os aprendizes já participam e nos quais já atuam em alguns domínios. Por isso, essas formas de abordagem são condizentes com a alfabetização na perspectiva do letramento; ou seja, visando-se a ele, mas não necessariamente no momento imediato.

Por sua vez, o Exemplo 2 ilustra uma outra possibilidade de associação de ambas as práticas, o que configuraria o "alfabetizar letrando", ou seja, a articulação e a simultaneidade das abordagens, compreendidas a partir do uso do gerúndio (CUNHA; CINTRA, [s.d.], p. 480; HOUAISS, 2001, p. 2575).

\section{Exemplo 2:}

As atividades de rotina que realizo em minha turma são: escrita da rotina do dia no quadro, escrita do nome da escola e data e marcação da data no calendário. Essas atividades são utilizadas para trabalhar a leitura, as relações grafofônicas e a criação de repertório de palavras estáveis. A escrita da rotina no quadro normalmente é a primeira atividade. Na maioria das vezes, eu escrevo os momentos que iremos ter durante a aula, mas os alunos também são convidados para serem meus escribas. Depois da escrita, sempre uma das crianças é convidada para fazer a leitura dos momentos que teremos durante 
o dia. Uma atividade não tão frequente, mas que também faço nesse momento de escrita da rotina, é escrever palavras com a troca ou falta de alguma letra para que os alunos encontrem o erro e as corrijam. A escrita da data já foi desenvolvida de três maneiras em nossa turma. A primeira, no início do ano, na qual eu escrevia (nome da escola, município e data) e, em seguida, realizava a leitura destacando as sílabas formadas. Em outro momento, atuei como escriba dos alunos com eles ditando como se escrevia cada palavra. Atualmente, um aluno é chamado para escrever no quadro e, em seguida, realizamos a leitura corrigindo os erros cometidos. No decorrer do ano, estou percebendo a importância dessas atividades para os alunos, principalmente para aqueles que ainda estão, ou estavam, na fase inicial do processo de alfabetização. Em muitos momentos, eles recorriam a palavras que escrevíamos durante a rotina para a escrita de outras. (Ano 2, Unidade 2, p. 23)

Como depreendemos pelo relato, um processo serve ao outro, mostra-se necessário para que o outro se realize, sendo esta a principal condição para se alfabetizar enquanto se letra ou o se letrar enquanto se alfabetiza: a realização do texto como contexto em que e por meio do qual os alunos aprendem sobre o sistema de escrita. Portanto, uma integração articulada; diferentemente do que aconteceu no primeiro exemplo, em que a abordagem linguística não contribuiu para que se alcançasse algum propósito comunicativo ou de interação, embora tenha sido válida para o objetivo a que visava.

No que diz respeito à abordagem discursiva, o registro da rotina diária é uma prática social de escrita que, inclusive, extrapola o universo escolar. Na experiência relatada, embora a professora crie circunstâncias para didatizar o ensino da escrita, a produção do texto sobrepuja esse objetivo e atende, primeiro, na percepção das crianças, à dinâmica da aula no dia, deixando-as cientes das atividades a serem desenvolvidas e tornando-as coparticipantes da organização do tempo na escola. Ou seja, não se trata, de forma alguma, de usar o texto como pretexto; ele serve, de fato, a um propósito real, de comunicação e interação.

Oscilando principalmente entre essas designações conceituais e didáticometodológicas, a maioria das atividades relatadas no material formativo não articula ensino sistemático do SEA e usos sociais da escrita. Num conjunto de 83 atividades que analisamos ${ }^{8}$, 66 delas (quase $80 \%$ ) foram contextualizadas, mas apenas 22 (cerca de $27 \%$ ) articularam as duas dimensões. Portanto, 61 atividades (quase $74 \%$ ) caracterizaram práticas do letramento escolar; assim, bastante distintas de outros usos da escrita nas vivências diárias dos aprendizes fora desse espaço. Visando exclusivamente à compreensão da lógica do sistema alfabético e de suas convenções, ou seja, ao desenvolvimento de habilidades individuais, alinham-se ao que Street (2014) denomina letramento autônomo. Supostamente, são conhecimentos que levam a mobilidade social e avanços cognitivos.

\footnotetext{
8 Dentre os relatos de atividades constantes no material formativo, foram analisados apenas aqueles que detalharam o modo como as atividades se realizaram nos contextos de sala de aula, permitindo-nos divisar os procedimentos didático-metodológicos que associaram ou não as práticas de alfabetização e letramento. Feito esse recorte, foram objeto de investigação 37 relatados, dos quais analisamos 83 atividades que os constituíram.
} 
Por fim, houve apenas dois relatos que se expandiram para discussões mais críticas, contribuindo para uma educação menos apolítica. Um deles corresponde à realização de um projeto didático intitulado "Meu bairro, quantos lugares". Alternando entre a articulação e a abordagem paralela de alfabetização e letramento, as professoras oportunizaram aos alunos vivências "encharcadas na realidade", apropriando-nos das palavras de Chassot (2016). Devido às limitações deste artigo e à extensão do relato, apresentamos fragmentos dele no Exemplo 3.

\section{Exemplo 3:}

[...] os alunos relataram oralmente os seus sentimentos em relação ao bairro onde moram: quais atividades gostam de fazer, quais lugares gostam de frequentar, o que gostariam que tivesse em seu bairro. Os relatos orais culminaram na produção de um texto escrito em que as crianças puderam registrar suas impressões. [...] Feito isso, as docentes trouxeram vários materiais e as crianças foram convidadas a pesquisar fotografias de seus bairros para ilustrar o texto escrito. [...] "Com suas falas pude perceber o que os alunos sentem e como percebem o bairro. Com isso, se sentem participantes do local onde moram propondo soluções significativas não só para eles como crianças, mas para toda a comunidade, pois os desenhos demonstraram um bairro ideal para todos e não só para as crianças, como se podia esperar dada a idade das mesmas. [ ...] A aula terminou com uma discussão sobre o estado de conservação desses lugares [ .... Os alunos foram estimulados a darem suas opiniões e justificarem. [...] $\mathrm{Na}$ sexta aula, como uma forma de intervir na realidade, as professoras lançaram para a turma a proposta da escrita de um panfleto com a finalidade de conscientizar a comunidade sobre os cuidados que devemos ter com o lugar onde moramos e também de uma carta para o Prefeito cobrando melhores condições para as pessoas que moram no bairro. Para ajudar os alunos a escreverem da melhor forma esses textos, as professoras realizaram antes algumas atividades explorando as características dos gêneros textuais. Em diferentes momentos, foram exploradas, principalmente, a representação da situação de comunicação (finalidade, interlocutor, sua própria posição como autor e o gênero), os aspectos composicionais e o tipo de linguagem adequada aos gêneros. [...] No último dia do projeto, os alunos fizeram a mobilização para a entrega dos panfletos no entorno da comunidade e também enviaram a carta de reclamação para o prefeito da cidade. (Ano 1, Unidade 5, p. 15-28.)

O diferencial nesse relato foi o exercício de cidadania oportunizado aos alunos, por meio de práticas de letramento para muito além do contexto escolar. Embora não se narrem os desdobramentos das ações realizadas, a experiência didática deixou claro que o uso da língua não é neutro (cf. PENNYCOOK, 2001; MOITA LOPES, 2009), assim como também não é neutro processo educativo e as escolhas a ele inerentes (FREIRE, 1989). A língua é mais que um instrumento, que um código. Ela é mediadora de interações sociais e constrói a vida social, num contexto marcado por relações de poder. Caso isso seja preterido, ajuda-se a fortalecer o percurso político e histórico da educação.

Abordagens pedagógicas como a relatada no Exemplo 3, que dão voz aos aprendizes e que envolvem questões sociais e relações de poder, representam um modelo alternativo de letramento, o ideológico (STREET, 2014). Este, aliás, é o que se pretende derrubado pelo governo atual, com a proposta de uma escola sem partido, sem qualquer viés ideológico. Mal sabem os leigos que qualquer fazer ou não fazer é atravessado por ideologias. 
Para que atividades como essas se façam mais presentes nos "chãos das escolas", é preciso que as formações docentes oportunizem o fortalecimento da autonomia do professor, para que ele, ciente do seu compromisso com a formação integral dos aprendizes, se faça constantemente autor crítico, inventivo de novas práticas, de novas possibilidades (DEMO, 2014). Fica, então, o questionamento: o PNAIC deu conta desse tipo de formação? É legítimo que as respostas para essa pergunta sejam ouvidas dos próprios professores alfabetizadores, segundo suas idiossincrasias.

\section{Implicações político-pedagógicas}

A análise das práticas de linguagem no contex to do PNAIC mostrou o predomínio de atividades que, na realidade, não articulam alfabetização e letramento. Os usos da língua escrita na escola ainda são informados, sobremaneira, pelo papel social que, histórica e culturalmente, foi estabelecido para essa instituição: um lugar dedicado ao desenvolvimento de habilidades individuais, de natureza técnica e, por isso, apolíticas. Esse protótipo de escola e de ensino comporta o modelo de letramento autônomo (STREET, 2014), coerente com as propostas governamentais de se investir em educação para melhorar as condições de vida da população e, assim, alavancar o país diante do cenário mundial.

Para esse cenário, sob a perspectiva da ANT, que prevê a ação simultânea de uma série de elementos para a construção de uma realidade, contribuem atores de campos diversos, envolvendo questões políticas, históricas e acadêmico-educacionais - permitindo-nos aqui um recorte dentro de inumeráveis possibilidades. Primeiramente, considerando-se as questões teórico-metodológicas, elas refletem os contextos de produção dos cadernos formativos, que congregam vozes de diferentes áreas, com a predominância da Pedagogia ou da Educação e da Psicologia Cognitiva, que têm o ensino da língua escrita como um dos campos de estudo e investigação. A Linguística Aplicada, reduto dos estudos dos letramentos, apenas mais recentemente passou a se dedicar à alfabetização e ainda não ganhou espaço importante na formação inicial de docentes. Essa é uma realidade que também contribuiu para que a faceta linguística ganhasse maior relevância nas atividades relatadas.

Com relação ao contexto histórico-educacional que antecedeu ao PNAIC e que contribuiu para que ele fosse instituído, não vemos como apropriado falar em "heranças" que permanecem nas salas de aula. Ainda que com limitações naturalmente esperadas, o programa rompe com práticas escolares, por longa data, muito mais inexpressivas, que não visavam à formação de leitores e produtores de textos. Afirma-se num dos cadernos que ainda é um desafio o "alfabetizar letrando", mas ratifica-se também a importância de 
se desenvolverem "práticas que contemplem as duas dimensões e que, na medida do possível, as articulem” (Ano 1, Unidade 5, p. 9-10. Destaques adicionados.). Logo, as formações, a partir do material didático que as orientou, inspiraram novos paradigmas. A expectativa é que estes tenham se frutificado a partir do saber fazer dos profissionais que participaram das formações; que possam ter sido aprofundados e revelar, ainda hoje, possibilidades pedagógicas mais audaciosas e dinâmicas em muitas escolas brasileiras.

Já no que diz respeito ao PNAIC como política pública, as opções didáticometodológicas que se apresentaram nos cadernos, ao não priorizarem a perspectiva crítica na escolarização, atendem satisfatoriamente às aspirações político-governamentais. A primazia da língua como código, como sistema supostamente neutro, é suficiente e até oportuna para um padrão homogêneo de ensino e de avaliação, ao mesmo tempo em que limita a formação crítica das pessoas, mantendo-as subjugadas à classe detentora de poder econômico e social.

Ademais, a "educação como formação", relacionada à vida, mais crítica e participativa, conforme pressupostos freireanos (FREIRE, 2018), pode demandar mais tempo na escola, o que a política capitalista neoliberal não tem. Também, requer currículos mais flexíveis, que, entretanto, deixariam mais volúveis os índices que atraem investimentos internacionais no país. Por isso, é mais vantajoso às instâncias governamentais contentar-se com uma "educação como treinamento" e, mais do que isso, insistir em práticas dessa natureza. Ela cerceia conflitos e construção de sentidos; ajuda a apagar as razões históricas para as altas taxas de analfabetismo, bem como causas outras que contribuem para a manutenção desse cenário.

\section{Considerações finais}

Infelizmente, no Brasil não há uma política de Estado para a educação. Esse campo fica, então, sujeito a intervenções político-partidárias, o que hoje se evidencia na defesa de uma alfabetização tecnicista, afastada dos usos sociais da escrita. Diante desse cenário, que implica retrocessos bastante sérios para a área da educação, este artigo retomou o extinto PNAIC, programa de formação docente continuada que defendia a alfabetização na perspectiva do letramento. O objetivo foi observar como o ensino sistemático da escrita foi relacionado ao tex to no material formativo do programa de 2013, ano em que se focalizou a alfabetização em língua portuguesa. A partir da teoria Ator-Rede, associamos influências de natureza acadêmico-educacional, políticas e históricas, todas elas necessariamente ideológicas.

Constatamos que o programa contribui para a valorização da dimensão linguística no processo de ensino-aprendizagem da língua escrita, nos moldes do letramento autônomo. Além de não priorizar enfrentamentos motivados por uma perspectiva mais crítica em relação 
aos contextos, a maior parte das práticas relatadas como exitosas nos cadernos formativos aborda de forma paralela o ensino do SEA e as práticas de leitura e escrita de textos, focalizando essas dimensões em momentos distintos. São práticas integradas, mas não articuladas, de modo que não conscientizam os aprendizes de que se aprende a ler e a escrever para interação nos diversos contextos sociais.

Assim, o programa rompe com as referências metodológicas de tempos de outrora, em que não se privilegiava a formação de leitores e escritores. Entretanto, reflete ainda interesses político-econômicos de tradição histórica no país, além de ainda mostrar a alfabetização como reduto do campo investigativo da Educação, já que a Linguística Aplicada, perspectiva sob a qual se desenvolvem os estudos dos letramentos, é incipiente na abordagem do tema.

Este artigo, então, contribui para a discussão das abordagens didáticas relacionadas à alfabetização, reiterando a necessidade de um processo de ensino-aprendizagem da língua escrita que não se restrinja às questões de natureza estrutural e linguística. O processo de aquisição da escrita alfabética e ortográfica deve acontecer muito proximamente dos processos de interação que acontecem fora dos muros escolares, considerando-se a língua como interação. E, principalmente, deve oportunizar a formação crítica dos alfabetizandos, para que possam, uma vez tendo se apropriado da escrita, atuar em favor de uma sociedade mais justa, mais engajada política e socialmente.

\section{Referências}

ALBUQUERQUE, Eliana Borges Correia de; MORAIS, Artur Gomes; FERREIRA, Andréa Tereza Brito. A relação entre alfabetização e letramento na Educação de Jovens e Adultos: questões conceituais e seus reflexos nas práticas de ensino e nos livros didáticos. In: LEAL, Telma Ferraz; ALBUQUERQUE, Eliana Borges Correia de; MORAIS, Artur Gomes (org.). Alfabetizar letrando na EJA: Fundamentos teóricos e propostas didáticas. Belo Horizonte: Autêntica, 2013. (Estudos em EJA). E-book, não paginado. Capítulo 1.

ANNUNCIATO, Pedro. A alfabetização no Brasil não avança. O Pnaic falhou? Nova Escola, 7 nov. 2017. Disponível em: https://novaescola.org.br/conteudo/7096/a-alfabetizacao-nobrasil-nao-avanca-sera-que-o-pnaic-falhou. Acesso em: 23 mar. 2021.

BRASIL. Ministério da Educação. Base Nacional Comum Curricular. Educação é a base. Terceira versão. Brasília: MEC, 2017a. Disponível em: http://basenacionalcomum.mec.gov.br/images/BNCC_EI_EF_110518_versaofinal_site.pdf. Acesso em: 30 mar. 2021.

BRASIL. Ministério da Educação. PNAIC - Pacto Nacional pela Alfabetização na Idade Certa: Documento Orientador 2017. Brasília, DF: MEC, 2017b. Disponível em: http://pacto.mec.gov.br/images/pdf/doc orientador/doc orientador versao final.pd.

Acesso em: 22 mar. 2021. 
BRASIL. Ministério da Educação. PNAIC em Ação 2017: Documento orientador. Brasília: MEC, SEB, 2017c. Disponível em:

http://pacto.mec.gov.br/images/pdf/doc_orientador/doc_orientador_versao_final.pdf.

Acesso em: 31 mar. 2021.

BRASIL. Ministério da Educação. PNAIC em Ação 2016: Documento orientador das ações de formação continuada de professores alfabetizadores em 2016. Brasília: MEC, SEB, 2016. Disponível em:

http://pacto.mec.gov.br/images/pdf/doc_orientador/documento_orientador_2016.pdf.

Acesso em: 23 mar. 2021.

BRASIL. Instituto Nacional de Estudos e Pesquisas Educacionais Anísio Teixeira. Avaliação Nacional da Alfabetização: relatório 2013-2014: volume 1: da concepção à realização. Brasília, DF: Inep, 2015a. 115 p.

BRASIL. Instituto Nacional de Estudos e Pesquisas Educacionais Anísio Teixeira. Plano Nacional de Educação PNE 2014-2024: Linha de Base. Brasília, DF: Inep, $2015 \mathrm{~b}$.

BRASIL. Lei ${ }^{\circ}$ 12.801, de 24 de abril de 2013. Dispõe sobre o apoio técnico e financeiro da União aos entes federados no âmbito do Pacto Nacional pela Alfabetização na Idade Certa e dá outras providências. Diário Oficial da União, Brasília, DF, p.1, 25 abr. 2013 a. Seção 1.

BRASIL. Portaria n. 90, de 6 de fevereiro de 2013. Define o valor máximo das bolsas para os profissionais da educação participantes da formação continuada de professores alfabetizadores no âmbito do Pacto Nacional pela Alfabetização na Idade Certa. Diário Oficial da União, Brasília, DF, p. 6, 7 fev. 2013b. Seção 1.

BRASIL. Ministério da Educação. Resolução/CD/FNDE n. 4, de 27 de fevereiro de 2013. Estabelece orientações e diretrizes para o pagamento de bolsas de estudo e pesquisa para a Formação Continuada de Professores Alfabetizadores, no âmbito do Pacto Nacional pela Alfabetização na Idade Certa. Diário Oficial da União, Brasília, DF, 2013c.

BRASIL. Ministério da Educação. Resolução/CD/FNDE nº 12, de 8 de maio de 2013. Altera dispositivos da Resolução CD/FNDE $n^{\circ}$ 4, de 27 de fevereiro de 2013, que estabelece orientações e diretrizes para o pagamento de bolsas de estudo e pesquisa para a Formação Continuada de Professores Alfabetizadores, no âmbito do Pacto Nacional pela Alfabetização na Idade Certa. Diário Oficial da União, Brasília, DF, 2013d.

BRASIL. Ministério da Educação. Secretaria de Educação Básica. Diretoria de Apoio à Gestão Educacional. Pacto Nacional pela Alfabetização na Idade Certa. A aprendizagem do sistema de escrita alfabética: ano 1: unidade 3. Brasília: MEC, SEB, 2012a.

BRASIL. Ministério da Educação. Secretaria de Educação Básica. Diretoria de Apoio à Gestão Educacional. Pacto Nacional pela Alfabetização na Idade Certa. A organização do planejamento e da rotina no ciclo de alfabetização na perspectiva do letramento: ano 2: unidade 2. Brasília: MEC, SEB, 2012 b.

BRASIL. Ministério da Educação. Secretaria de Educação Básica. Diretoria de Apoio à Gestão Educacional. Pacto nacional pela alfabetização na idade certa. Formação do professor alfabetizador. Caderno de apresentação. Brasília: MEC, SEB, 2012c. 
BRASIL. Ministério da Educação. Medida Provisória n. 586, de 8 de novembro de 2012. Dispõe sobre o apoio técnico e financeiro da União aos entes federados no âmbito do Pacto Nacional pela Alfabetização na Idade Certa, e dá outras providências. Diário Oficial da União, Poder Executivo, Brasília, DF, 9 nov. 2012d.

BRASIL. Ministério da Educação. Secretaria de Educação Básica. Diretoria de Apoio à Gestão Educacional. Pacto nacional pela alfabetização na idade certa. O trabalho com gêneros textuais na sala de aula: ano 1, unidade 5. Brasília: MEC, SEB, $2012 \mathrm{e}$.

BRASIL. Ministério da Educação. Portaria n. 867, de 4 de julho de 2012. Institui o Pacto Nacional pela Alfabetização na Idade Certa e as ações do Pacto e define suas diretrizes gerais. Diário Oficial da União, Brasília, DF, 5 jul. 2012 f. Seção 1, n. 129.

BRASIL. Emenda Constitucional n. 59, de 11 de novembro de 2009. Diário Oficial da União, Brasília, DF, 12 nov. 2009. p. 8. Disponível em:

http://www.planalto.gov.br/ccivil 03/constituicao/emendas/emc/emc59.htm. Acesso em: 24 mar. 2021.

CHASSOT, Attico. Alfabetização Científica: questões e desafios para a educação. 7. ed. Ijuí: Unijuí, 2016. 344 p. (Coleção educação em ciências.)

CUNHA, Celso; CINTRA, Luís Filipe Lindley. Nova gramática do português contemporâneo. 2. ed. 40. impr. Rio de Janeiro: Nova Fronteira, [s. d.].

DEMO, Pedro. Educação e alfabetização científica. Campinas, SP: Papirus, 2014.

DICKEL, Adriana. A Avaliação Nacional da Alfabetização no contex to do Sistema de Avaliação da Educação Básica e do Pacto Nacional pela Alfabetização na Idade Certa: responsabilização e controle. Cadernos Cedes, Campinas, v. 36, n. 99, p. 193-206, maio-ago., 2016.

ESTEBAN, Maria Teresa. Considerações sobre a política de avaliação da alfabetização: pensando a partir do cotidiano escolar. Revista Brasileira de Educação, [Rio de Janeiro?], v. 17, n. 51, p. 573-592, set./dez. 2012. DOI: https://doi.org/10.1590/s1413$\underline{24782012000300005 .}$.

FREIRE, Paulo. Pedagogia dos sonhos possíveis. Organização Ana Maria Araújo Freire. 2. ed. Rio de Janeiro; São Paulo: Paz e Terra, 2018.

FREIRE, Paulo. A importância do ato de ler: em três artigos que se completam. 23. ed. São Paulo: Autores Associados: Cortez, 1989.

FREITAS, Mirella de Oliveira. Enfrentamentos político-pedagógicos no Pacto Nacional pela Alfabetização na Idade Certa (PNAIC): desafios de alfabetizar letrando. 2019. Tese (Doutorado em Letras) - Universidade Federal do Tocantins, Araguaína, 2019.

HOUAISS, Antônio; VILLAR, Mauro de Salles. Dicionário Houaiss da Lingua Portuguesa. Rio de Janeiro: Objetiva, 2001.

LATOUR, Bruno. Reagregando o social. Salvador: Edufba, 2012. Bauru; São Paulo: Edusc, 2012. 
LEÃO, Silse Teixeira de Freitas Lemos. Breve análise sócio-histórica da política educacional brasileira: ensino fundamental. In: JORNADA INTERNACIONAL DE POLÍTICAS PÚBLICAS, 2., 2005. Anais... São Luiz, MA: UFMA, 2005. Disponível em: https://www.yumpu.com/pt/document/read/12540377/breve-analise-socio-historica-dapolitica-educacional-brasileira. Acesso em: 18 mar. 2021.

MOITA LOPES, Luiz Paulo da. Da aplicação de linguística à Linguística Aplicada indisciplinar. In: PEREIRA, Regina Celi; ROCA, Pilar (org.). Linguística Aplicada: um caminho com diferentes acessos. São Paulo: Contexto, 2009. p. 11-24.

MORAIS, Artur Gomes de. A consciência fonológica de alfabetizandos jovens e adultos e sua relação com o aprendizado da escrita alfabética. In: LEAL, Telma Ferraz; ALBUQUERQUE, Eliana Borges Correia de; MORAIS, Artur Gomes (org.). Alfabetizar letrando na EJA: Fundamentos teóricos e propostas didáticas. Belo Horizonte: Autêntica, 2013. (Estudos em EJA). E-book, não paginado. Capítulo 3.

MORAIS, Artur Gomes de. Sistema de Escrita Alfabética. São Paulo: Melhoramentos, 2012. (Como eu ensino). E-book.

MORAIS, Artur Gomes de. Se a escrita alfabética é um sistema notacional (e não um código), que implicações isso tem para a alfabetização? In: MORAIS, Artur Gomes de; ALBUQUERQUE, Eliana Borges Correia de; LEAL, Telma Ferraz. Alfabetização: apropriação do sistema de escrita alfabética. Belo Horizonte: Autêntica, 2005. p. 29-46.

MORAIS, Artur Gomes de; ALBUQUERQUE, Eliana Borges Correia de. Alfabetização e Letramento: O que são? Como se relacionam? Como alfabetizar letrando? In:

ALBUQUERQUE, Eliana B. C. e LEAL, Telma F. (org.) Alfabetização de jovens e adultos em uma perspectiva de letramento. Belo Horizonte: Autêntica, 2010.

MORAIS, Artur Gomes de. Alfabetização e letramento: o que são? como se relacionam? como alfabetizar letrando? In: LEAL, Telma Ferraz e ALBUQUERQUE, Eliana Borges Correia de (org.). Alfabetização de jovens e adultos em uma perspectiva de letramento. Belo Horizonte: Autêntica, 2004.

PENNYCOOK, Alastair. Critical Applied Linguistics: A Critical Introduction. Critical Applied Linguistics: A Critical Introduction. Mahwah, New Jersey: Lawrence Erlbaum Associates, 2001.

PERES, Eliane. "A produção da crença”: políticas de alfabetização no Brasil na última década (2006-2016). In: ASSOCIAÇÃO NACIONAL DE PÓS-GRADUAÇÃO E PESQUISA EM EDUCAÇÃ̃ SUL, 2016, 11., Curitiba - PR. Anais... Curitiba, PR: UFPR-ANPEDSul, 2016. v. 1. p. 1-16. Disponível em: http://www.anpedsul2016.ufpr.br/portal/wpcontent/uploads/2015/11/Eixo-7-Alfabetiza\%C3\%A7\%C3\%A30-e-Letramento.pdf. Acesso em: 19 mar. 2021 . DOI: https://doi.org/10.22239/2317-269x.01620.

PINTO, Clovis Cerretto. Mudança nas Organizações e a Teoria Ator-Rede: humanos e nãohumanos em controvérsias. São Paulo: Mackenzie, 2016.

SILVA, Wagner Rodrigues. Letramento ou literacia: ameaças da cientificidade. In: SILVA, Wagner Rodrigues (org.). Contribuições sociais da Linguística Aplicada: uma homenagem a Inês Signorini. Campinas: Pontes Editores, 2021, v. 1. p. 111-162. 
Revista Educação e Políticas em Debate - v. 10, n. 2, p. 575-594, mai./ago. 2021 - ISSN 2238-8346

SOARES, Magda Becker. Letramento: um tema em três gêneros. Belo Horizonte: Autêntica, 1998.

SOARES, Magda Becker. A reinvenção da alfabetização. Presença Pedagógica, Belo Horizonte, v. 9, n. 52, p. 15-21, jul./ago. 2003 a.

SOARES, Magda Becker. Alfabetização e letramento. São Paulo: Contex to, 2003b.

SOARES, Magda Becker. Letramento e alfabetização: as muitas facetas. In: 26., REUNIÃO NACIONAL DA ANPED, 2003, Caxambu. Anais... Caxambu: [s.n.], 2003c, p. 1-18.

SOARES, Magda Becker. Letramento e escolarização. In: RIBEIRO, Vera Masagão (Org.). Letramento no Brasil: reflexões a partir do INAF 2001. São Paulo: Global, 2003d.

SOARES, Magda Becker. Letramento e alfabetização: as muitas facetas. Revista Brasileira de Educação, Rio de Janeiro, n. 25, p. 5-17, jan./fev./mar./abr. 2004. DOI:

https://doi.org/10.1590/s1413-24782004000100002.

SOARES, Magda Becker. Alfabetização e letramento. São Paulo: Contexto, 2006.

SOARES, Magda Becker. Letramento e alfabetização: as muitas facetas. Belo Horizonte, Autêntica, 2009.

SOARES, Magda Becker. Alfabetização: a questão dos métodos. São Paulo: Contexto, 2016.

SOARES, Magda Becker. Alfabetização e letramento. 7. ed. rev. e ampl., 1. reimp. São Paulo: Contexto, 2017.

STREET, Brian V. Letramentos Sociais: abordagens críticas do letramento no desenvolvimento, na etnografia e na educação. Tradução Marcos Bagno. São Paulo: Parábola Editorial, 2014.

VIEIRA, Sofia Lerche. Políticas de Formação em Cenários de Reforma. In: AMARAL, Ana Lúcia; VEIGA, Ilma Passos A. Formação de Professores: Políticas e Debates. Campinas, SP: Papirus, 2016. (E-book). 